\title{
Prevalence, associated factors, and outcomes for labor induction at a tertiary hospital in Northern Tanzania: A retrospective cohort study 2000 - 2015
}

\section{Clifford Silver Tarimo}

Kilimanjaro Christian Medical University College https://orcid.org/0000-0002-0672-9471

Jian Wu ( $\square$ wujian@zzu.edu.cn )

Joseph Obure

Kilimanjaro Christian Medical Centre

Michael Johnson Mahande

Kilimanjaro Christian Medical University College

\section{Research article}

Keywords: Labour induction, Outcomes, Associated factors, north Tanzania

Posted Date: June 8th, 2020

DOI: https://doi.org/10.21203/rs.3.rs-27915/v1

License: (1) (1) This work is licensed under a Creative Commons Attribution 4.0 International License. Read Full License 


\section{Abstract \\ Background}

Labor induction ( $\mathrm{IOL}$ ) refers to an obstetric intervention which include artificial stimulation of uterine contraction aiming at vaginal delivery of a fetus before the onset of spontaneous labor. Despite undisputed importance of this intervention in improving pregnancy outcomes, data on its utilization and outcomes in Tanzania is limited. The aim of this study was to determine the prevalence, associated factors and outcomes for labor induction among women who were attended at a tertiary hospital in north-Tanzania.

\section{Methods}

We designed a retrospective cohort study and analyzed 53338 deliveries at the Kilimanjaro Christian Medical Centre (KCMC) between the year 2000 to 2015. We enrolled singleton deliveries with vertex presentation and excluded observations with missing information on induction status. Relative risk and 95\% Confidence Interval for risk factors and outcomes of labor induction were estimated using log-binomial regression models. Robust variance estimation was used to account for repeated deliveries from the same subject.

\section{Results}

53,338 deliveries were analyzed. Prevalence of labor induction was $21.63 \%$. Independent risk factors for labor induction were; postdates ( $\mathrm{RR}=1.21 ; 95 \% \mathrm{Cl}$ : $1.15-1.28)$, fetal macrosomia $(\mathrm{RR}=1.27 ; 95 \% \mathrm{Cl}: 1.18-$ 1.36) and obesity ( $R R=1.12 ; 95 \% \mathrm{Cl}: 1.06-1.18)$. Labor induction was associated with an increased risk of uterine rapture $(\mathrm{RR}=1.84 ; 95 \% \mathrm{Cl}: 1.62-2.09)$ and low $(<7)$ Apgar score $(\mathrm{RR}=1.27 ; 95 \% \mathrm{Cl}: 1.17-1.37)$. Labor induction offered protective effect against cesarean delivery ( $\mathrm{RR}=0.56 ; 95 \% \mathrm{Cl}: 0.53-0.58)$ and admission to neonatal intensive care unit $(\mathrm{RR}=0.94 ; 95 \% \mathrm{Cl}$ : $0.89-0.99)$.

\section{Conclusion}

Efforts aimed at achieving the health-related sustainable development goals should focus on increasing access to effective interventions as well as improving quality of health care while being cautioned on likelihood of adverse maternal and fetal outcomes.

\section{Background}

Labor induction (IOL) refers to an obstetric intervention which include artificial stimulation of uterine contraction aiming at vaginal delivery of a fetus before the onset of spontaneous labor [1-3]. The procedure can either be achieved mechanically or by the use of pharmaceuticals readily available in the market such as oxytocin infusions and prostaglandins [4]. Mechanical induction methods include balloon 
catheter, amniotomy and membrane sweeping [5-6]. A physician provides booking appointment to a pregnant woman for IOL due to maternal, fetal, social indications or combination of all these factors [7]. Given the increasing attention to reduce perinatal morbidity and mortality, the rates of IOL have continued to rise over the past few decades [8]. Globally, the prevalence of IOL varies greatly between countries and regions but higher rates have been reported in developed countries than in developing countries [9-10]. The IOL accounts for approximately $20 \%$ of deliveries in the UK and USA, but the rates have been rising steadily since the past decade $[11,12]$. The rate of IOL for Africa region currently stands at $4.4 \%$, confirming the lowest rates for this important intervention in the low resourced setting [13]. The low rates of IOL in Africa may be reflecting the observed high perinatal mortality rates in the region which stands at 56 per 1000 live births, making Africa to be rated the highest in all WHO regions worldwide [14].

Major indications for IOL comprises of postdates, intra uterine growth restrictions (IUGR), fetal macrosomia, oligohydramnios, isoimmunization, gestational diabetes, chorioamnionitis, pre-labor rapture of membranes (PROM), hypertensive disorders of pregnancy and other maternal conditions [15-17]. However, the World Health Organization recommends IOL as a therapeutic option only when the benefits of termination of pregnancy surpass the risks of its continuation [18]. Despite undisputed importance of IOL for terminating pregnancies in which there is a risk to the mother or/and fetus, this intervention may result in unprecedented effects [19].

Myriad of studies have shown an association between IOL and adverse pregnancy outcomes including emergence cesarean section (CS) delivery for patients with unfavorable cervix, instrumental vaginal delivery, blood transfusion, longer hospital stay, and admission to intensive care unit (ICU) [19, 20]. Some studies also have demonstrated higher rates of adverse outcomes associated with IOL such as prolonged first stage of labour, failure to progress of labour, intrapartum hemorrhage, admission to neonatal intensive care unit (NICU) and higher incidences of assisted vaginal births [21, 22, 23, 24]. Despite the fact that the IOL has potentials for preventing maternal complications and improving birth outcomes, its utilization in health facilities in African region is still very low, indicating a high unmet need for IOL in most countries of Africa including Tanzania [25]. The current study aims at determining the prevalence, risk factors and outcomes for labor induction among women who gave birth at a tertiary hospital in north-Tanzania.

\section{Methods}

\section{Study Setting}

We conducted this study at the tertiary hospital in north Tanzania called the Kilimanjaro Christian Medical Centre (KCMC). The hospital is located in the Kilimanjaro region and is one of the four referral hospitals in a country of over 50 million. The region constitutes of over 1.64 million inhabitants whom a significant proportion of this number, depends solely on this institution for a number of medical services including delivery, pediatrics, internal medicine and much more. Apart from serving the indigenous, the obstetrics patients served by this institution come from a more than seven diversified regions including some districts from a neighboring country Kenya. The hospital conducts over 4000 deliveries per year. In collaboration with Norwegian government, the hospital's obstetric department developed with an electronic database for 
maintaining all clinical and socio-demographic information of women who were admitted for delivery starting from the year 2000 to date.

\section{Data Source}

The medical registry of KCMC collects information from all women who deliver at the department of obstetrics and gynecology within 24 hours. Daily interviews are conducted by specially trained nurses using a standardized questionnaire. Records from the hospital birth registry database covers socio-demographic information, mother's health status before and after delivery. Socio demographic information in this database include maternal age, occupation, education level, marital status plus many others. Coverage on clinical information include parity status, use of induction, indications for IOL, induction methods and others [26].

\section{Statistical Analyses}

Data analysis was performed using STATA/IC (version 14, College Station, TX). We used frequencies to describe maternal socio-demographic characteristics as well as clinical information. Pearson chi-squared test was used to determine association between a set of independent variables and IOL status in bivariate analysis. Multivariable log-binomial regression models were used to estimate relative risks (RR) for IOL with $95 \%$ confidence intervals $(\mathrm{Cl})$ and its associated adverse outcomes. A $p$-value of less than 0.05 (2-tailed) was considered statistically significant for both univariate and multivariable analyses. Clustered analyses with robust estimation of variances was used to control for repeated deliveries.

\section{Results}

Prevalence and trend of induced deliveries at KCMC hospital (2000-2015)

A total of 53,338 deliveries were analyzed. Of these, $11,538(21.63 \%)$ were induced. We elucidated the trend of IOL over 16 years since the establishment of the KCMC medical birth registry (Fig. 1). There was a nonuniform trends of labor induction intervention throughout this period. The higher proportions of IOL were observed during the years 2005, 2006 and 2007 (33.3\%, 31.8\% and 30.4\%, respectively) compared to other years. Conversely, a decline in IOL was observed from $30.4 \%$ in 2007 to $7.5 \%$ in 2009

\section{Socio-demographic Characteristics Of Study Participants}

The sociodemographic characteristics of study participants are described in Table 1. The mean maternal age of the participants was $27(S D=6)$ years. More than half $(54 \%)$ were aged between 20 and 30 years and had primary education (57\%). Majority ( $87 \%$ ) were married. More than half $(56 \%)$ of women were multiparous, with majority $(64 \%)$ had normal birthweight babies. 


\begin{tabular}{|c|c|c|c|}
\hline Characteristic & $\begin{array}{l}\text { Induced delivery } \\
\text { n (\%) }\end{array}$ & $\begin{array}{l}\text { Spontaneous delivery } \\
\mathrm{n}(\%)\end{array}$ & $\chi^{2} p$-value \\
\hline Maternal age (years) & $1091(9.46)$ & $3458(8.27)$ & $<0.001$ \\
\hline$<20$ & $6786(58.81)$ & 22239 (53.20) & \\
\hline $20-30$ & $2284(19.80)$ & $9515(22.76)$ & \\
\hline $30-35$ & 1365 (11.83) & $6528(15.62)$ & \\
\hline$>35$ & $12(0.10)$ & $60(0.14)$ & \\
\hline \multicolumn{4}{|l|}{ Missing } \\
\hline Multiple gestation & 11106 (96.26) & $39380(94.21)$ & $<0.001$ \\
\hline No & $416(3.61)$ & $2359(5.64)$ & \\
\hline Yes & $16(0.14)$ & $61(0.15)$ & \\
\hline \multicolumn{4}{|l|}{ Missing } \\
\hline Education status & $144(1.25)$ & $955(2.28)$ & $<0.001$ \\
\hline None & $5771(50.02)$ & $24374(58.31)$ & \\
\hline Primary & 1502 (13.02) & $4688(11.22)$ & \\
\hline Secondary & 4095 (35.49) & 11689 (27.96) & \\
\hline Higher & $26(0.23)$ & $94(0.22)$ & \\
\hline \multicolumn{4}{|l|}{ Missing } \\
\hline Religion & $4460(38.65)$ & $15500(37.08)$ & $<0.001$ \\
\hline Catholic & $4723(40.93)$ & $17015(40.71)$ & \\
\hline Protestant & $2355(20.41)$ & $9285(22.21)$ & \\
\hline \multicolumn{4}{|l|}{ Muslim } \\
\hline Gestational age & $8326(72.16)$ & $29342(70.20)$ & $<0.001$ \\
\hline Term & $1174(10.18)$ & $5666(13.56)$ & \\
\hline Preterm & $1212(10.50)$ & $3135(7.50)$ & \\
\hline Post-term & $826(7.16)$ & 3657 (8.75) & \\
\hline Missing & & & \\
\hline
\end{tabular}




\begin{tabular}{|llll|}
\hline \multicolumn{4}{|l}{ Table 1: Socio-demographic characteristics of study participants $(\mathbf{N}=53,338)$} \\
\hline Parity & $6571(56.95)$ & $16610(39.74)$ & $<0.001$ \\
Primiparity & $4967(43.05)$ & $25190(60.26)$ & \\
Multiparity & & & \\
Body mass index & $1658(14.37)$ & $5795(13.86)$ & \\
Underweight & $4238(36.73)$ & $15173(36.30)$ & \\
Normal & $2677(23.20)$ & $9129(21.84)$ & \\
Overweight & $2447(21.21)$ & $9015(21.57)$ & \\
Obese & $518(4.49)$ & $2688(6.43)$ & \\
Missing & & \\
Birthweight & $1196(10.37)$ & $5930(14.19)$ & \\
Low & $7423(64.34)$ & $26691(63.85)$ \\
Normal & $2879(24.95)$ & $8995(21.52)$ \\
High & $40(0.35)$ & $184(0.44)$ \\
Missing & & \\
\hline
\end{tabular}

\section{Associated Factors For Labor Induction At KCMC Hospital}

The factors associated with IOL are shown in Table 3. We found that primiparity, advanced maternal age, postdates, high birthweight and obesity were independent risk factors for IOL. In the adjusted analyses, primiparous women had $77 \%$ (RR 1.77, 95\% Cl: 1.70-1.83) increased risk of IOL compared to their multiparous counterparts. Post term pregnancies women (>42 weeks) had 21\% (RR 1.21, 95\% Cl: 1.151.28 ) increased risk for IOL compared to term pregnancies. Mothers with big babies (>4 kg) had $27 \%$ (RR 1.27, 95\%: 1.18-1.36) increased risk of labor induction compared to women who delivered normal weight babies. Similarly, women who delivered low birth weight babies also had increased risk of being induced during labor. Obese women $\left(>30 \mathrm{~kg} / \mathrm{m}^{2}\right)$ had an elevated risk of $12 \%$ compared to women with normal body mass index (BMI). Maternal age offered protection against risks to IOL. 
Table 2

Crude and adjusted effects on risk factors for labor induction at KCMC hospital (2000-2015)

\begin{tabular}{|c|c|c|c|c|}
\hline Characteristics & Crude RR $\left(95 \% \mathrm{Cl}^{+}\right)$ & p-value & Adjusted RR $\left(95 \% \mathrm{Cl}^{+}\right)$ & $p$-value \\
\hline Parity & Ref & 0.001 & Ref & $<0.001$ \\
\hline Multiparity & $1.72(1.67-1.78)$ & & $1.77(1.70-1.83)$ & \\
\hline \multicolumn{5}{|l|}{ Primiparity } \\
\hline Maternal age(years) & Ref & 0.37 & Ref & $<0.001$ \\
\hline $20-30$ & $1.03(0.97-1.08)$ & $<0.001$ & $0.84(0.79-0.90)$ & 0.031 \\
\hline$<20$ & $0.83(0.79-0.86)$ & $<0.001$ & $0.95(0.90-0.99)$ & 0.008 \\
\hline $30-35$ & $0.74(0.70-0.78)$ & & $0.91(0.85-0.98)$ & \\
\hline \multicolumn{5}{|l|}{$>35$} \\
\hline Gestational age & Ref & $<0.001$ & Ref & $<0.001$ \\
\hline Term & $0.78(0.73-0.82)$ & $<0.001$ & $0.87(0.82-0.93)$ & $<0.001$ \\
\hline Preterm & $1.26(1.20-1.33)$ & & $1.21(1.15-1.28)$ & \\
\hline \multicolumn{5}{|l|}{ Post-term } \\
\hline Birthweight & Ref & $<0.001$ & Ref & $<0.001$ \\
\hline Normal & $0.77(0.73-0.82)$ & $<0.001$ & $1.14(1.07-1.21)$ & $<0.001$ \\
\hline Low & $1.11(1.07-1.16)$ & & $1.27(1.18-1.36)$ & \\
\hline \multicolumn{5}{|l|}{ Macrosomic } \\
\hline Body mass index & Ref & 0.463 & Ref & $<0.001$ \\
\hline Normal & $1.02(0.97-1.07)$ & 0.082 & $1.14(1.08-1.20)$ & 0.044 \\
\hline Underweight & $1.04(0.98-1.08)$ & 0.319 & $1.05(1.00-1.10)$ & $<0.001$ \\
\hline Overweight & $0.98(0.94-1.02)$ & & $1.12(1.06-1.18)$ & \\
\hline Obese & & & & \\
\hline
\end{tabular}

\section{Pregnancy Outcomes Associated Labor Induction At KCMC Hospital}

Crude and adjusted effects for pregnancy outcomes associated with IOL are shown in Table 3. We found that mothers who underwent IOL had $27 \%$ (RR 1.27, 95\% Cl: 1.17-1.37) an increased risk of having infants with Apgar scores at 5 th minutes and. They also have lower risk of Caesarean Section delivery (RR 0.56, 
$95 \% \mathrm{Cl}: 0.53-0.58)$; uterine rapture (RR $1.84,95 \% \mathrm{Cl}: 1.62-2.09)$ and newborn admission to intensive care unit [NICU] (RR 0.94, 95\% Cl: 0.89-0.99) compared to women who had spontaneously vaginal delivery.

Table 3

Associated clinical outcomes for labor induction (IOL) at KCMC ( $\mathrm{N}=53338)$

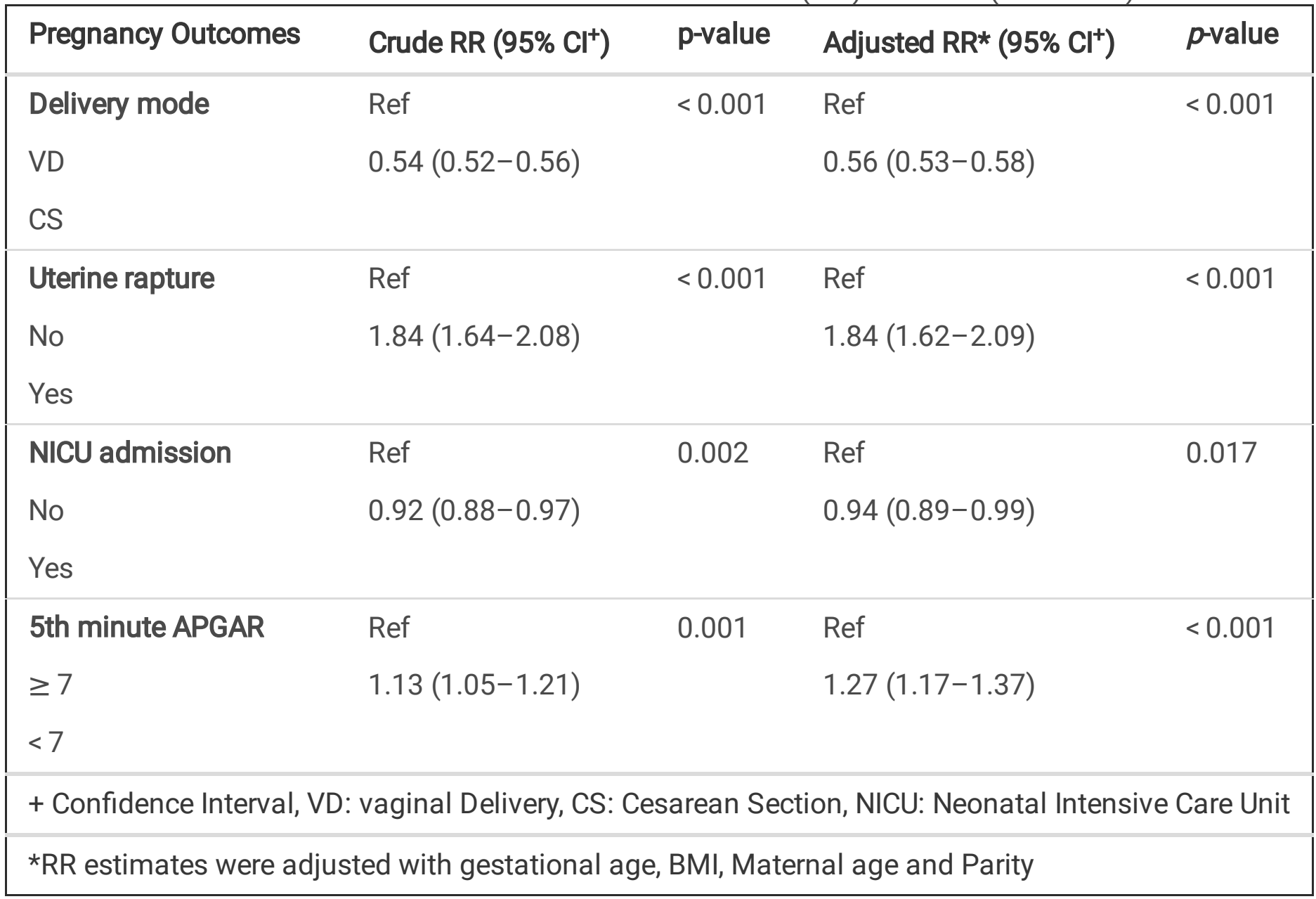

\section{Discussion}

In this study, the prevalence of labor induction was $21.63 \%$. This proportion was lower compared to previous hospital-based studies and national surveys conducted in developed countries [27]. This difference could be attributed to existing high unmet need for IOL that prevails in most resourceconstrained settings including Tanzania [13]. However, the prevalence of IOL in our study was higher compared to the previous report in Latin America, which reported the IOL prevalence of $11.4 \%$ [28]. The authors in the previous report attributed low prevalence of IOL with poor utilization of the prenatal care services coupled with low prevalence of institutional deliveries. This might not be the case in the present study where the ANC attendance is high in the study area.

As several literatures have reported on obstetric complications facing primiparous women such as prolonged delivery, and emergency cesarean section [29-31]. This is consistence with our study, but in contrast with some previous studies which reported the protective effect of nulliparity against IOL [32-34]. The high risk of IOL among primiparous women could be explained by the fact that first time pregnancies 
are often subjected to obstetric complications due to the fact that the mother's body is adjusting to a number of physiological changes. We also found that, maternal age categories considered have a protective effect on IOL. Similar has been reported elsewhere [32,33,35,36], but it was in contrast with previous study in Latin America, where the authors did not find any association between IOL and maternal age [37]

Some studies have reported on the association between IOL and post-term pregnancies [37,38]. This could be explained by the clinicians' tendency to recommend/prefer performing among post-date mothers IOL to ensure the safety of mother and an infant. In addition, the World Health Organization (WHO) recommends induction of labor (IOL) for women who have reached 41 completed weeks of pregnancy without spontaneous onset of labor. In some cases, postdate pregnancies may need IOL intervention, which of course comes with its own set of risks. In the present study, the post-date women had $21 \%$ of IOL compared to term women. Similar finding was reported elsewhere [38]. Evidence showed that, after 42 weeks of gestation, the placenta which supplies the baby with nutrients and oxygen from the mother starts aging and eventually fails, this necessitate the IOL to facilitate delivery of the baby [39]. In addition, post-term pregnancies is related to uterine overstimulation and fetal distress. This situation may necessitate a need for IOL intervention.

Macrosomic fetuses are at increased risk of obstetric complications, and notably shoulder dystocia, responsible for a severe neonatal morbidity. We found a $27 \%$ increased risk of IOL among women with babies weighing $>3.5$ kilogram compared to those with normal weights $(2.5-3.5)$ kilograms. IOL in deliveries that included macrosomic fetuses is done to reduce the risk of cesarean delivery for cephalopelvic disproportion and shoulder dystocia [40]. This could be the case for the observed association between IOL and delivery of macrosomic fetuses in our study.

Maternal obesity has been associated by with not only adverse outcomes for mothers and newborns but also to a need of additional obstetric interventions like IOL $[41,42]$. The current study revealed that there was a $12 \%$ an increased risk of IOL among obese women compared to those with normal BMI. This finding was in line with previous studies [43]. It is hypothesized that obese condition may lead to a lower Bishop score at presentation, hence necessitating a need for inducing labor.

Despite undisputed importance of IOL intervention in improving pregnancy outcomes, it can sometimes lead to unprecedented adverse health outcomes. A previous study conducted among low-risk nulliparous woman did not result in a significantly lower frequency of a composite adverse perinatal outcome, but it showed a significantly lower frequency of cesarean delivery [29]. However, a pooled analysis of observational studies conducted by Sanchez and colleagues suggested that women who were managed expectantly were more likely to deliver spontaneously compared to women who underwent IOL intervention [45]. The possible explanation for difference in findings between studies might be attributed to the difference in sample sizes. CS delivery following labor induction may be due to failure in labor progression, shoulder dystocia, or fetal macrosomia [46]. 
The current study found a protective effect of IOL for NICU admissions. These findings corroborate with a secondary analysis using the WHO database that showed a reduced risk of NICU admission among induced deliveries when compared with those who were managed expectantly [47]. In addition, IOL suggested a reduced rate of NICU admission in a previous study by the National Institute of Child Health and Human Development [48]. In contrast, a retrospective cohort study in Scotland revealed an increased NICU admissions that followed IOL [49]. These differences might be attributable to the difference in sample size as well as the nature of the study setting (hospital vs. population-based) and country policies that govern the provision of health service.

In the present study, we found that after adjustment for all predictor variables, induced deliveries showed a $27 \%$ an increased risk of delivering an infant with Apgar score of $<7$ at 5 th minute compared to spontaneous delivery. This was in contrast with a previous study conducted in the Latin America where the authors found no difference between these two groups [37]. Our study also found $84 \%$ increased risk of uterine rapture among women who had induced deliveries. This was consistent with previous investigators $[50,51]$. Rapturing of the uterus among women who were induced may possibly be fueled by elevated action of uterotonic agents that causes building up of pressure that causes mother's uterus to tear [52].

\section{Strength And Limitations}

The study is much advantaged by the huge number of participants enrolled for over sixteen consecutive years. This made this study to have a large statistical power to detect the true effect of IOL on study outcomes as well as associated factors. However, we could not assess the influence of cervical ripeness on IOL intervention as modeled in a previous study [55] due to its missingness in this database. Nevertheless, the study calls upon a prospectively designed study that will model the effect of bishop score on neonatal and maternal outcomes at this institution.

\section{Conclusion}

In this study, IOL was practiced at a rate which is almost similar to that of developed countries. We found numerous factors were associated with $\mathrm{IOL}$ including obesity, nulliparity, postdatism, and fetal macrosomia. We also found that IOL to be associated with adverse outcomes such as caesarean delivery, low Apgar scores and uterine rapture. This calls upon close consideration to be taken such that benefits of this intervention outweigh risks of adverse maternal outcomes. Measures also should be put forward to reduce the risk for IOL.

\section{Abbreviations}

Apgar: Activity Pulse Grimace Appearance Respiration; BMI: Body Mass Index; Cl: Confidence Interval; CS: Cesarean Section; ICU: Intensive Care Unit; IOL: Induction of labor; IUGR: Intrauterine Growth restriction; KCMC: Kilimanjaro Christian Medical Centre; KCMUCo: Kilimanjaro Christian Medical University College; NIMR: National Institute of Medical Research; NICU: Neonatal Intensive Care Unit; PROM: Pre-labor Rapture 
of Membrane; RR: Relative Risk; SDG: Sustainable Development Goals; VD: Vaginal Delivery; WHO; World Health Organization

\section{Declarations}

\section{Ethics approval and consent to participate}

The birth registry at KCMC has ethical clearance from mainly four (4) bodies which are; Tanzania Ministry of Health, National Institute for Medical research (NIMR), the Norwegian National Ethics Committee and form Kilimanjaro Christian Medical University College (KCMUCo). The current study is solely based on the KCMC Birth Registry established as a collaborative project between the University of Bergen, Norway and KCMC.

\section{Consent for publication}

Not Applicable

\section{Availability of data and materials}

Data used in this study can be shared only on reasonable request

\section{Competing Interests}

The authors declare to have no competing interests.

\section{Funding}

Funds for this study was secured by CST from German Academic Exchange Services (DAAD), Special Initiative SFBFR (2015): reference number 57220758. Funders had no influence of any form on the design, analysis or interpretations of the study findings.

\section{Authors' Contributions}

CST conceived the study topic, designed the study, analysed and drafted the manuscript. JW provided an extended insight on methodology, facilitated the write-up, and substantially reviewed the first and final version of the manuscript. JO co-supervised and provided technical experience in obstetrics. MJM supervised and provided statistical expertise. All authors read and approved the final version of the manuscript.

\section{Acknowledgements}


We are grateful to all workers at the birth registry unit of the KCMC and the Norwegian birth registry for their substantial support in data management and retrieval. Special thanks to all the study participants and nurses who gave their time and talents to make this study a successful one.

\section{References}

1. American College of Obstetricians and Gynecologists (ACOG practice bulletin). Induction of labor. Obstet Gynecol. 2009; 114:386-397.

2. MacKenzie JZ. Induction of labor at the start of the new millennium. Reproduction. 2006; 131:989998.

3. Sanchez-Ramos L. Induction of labor. Obstet Gynecol Clin N Am. 2005; 32: 181-200.

4. Mozurkewich EL, Chilimigras JL, Berman DR, Perni UC, Romero VC, King VJet al. Methods of induction of labour: a systematic review. BMC Pregnancy Childbirth. 2011; 11,

5. Heinemann J, Gillen G, Sanchez-Ramos L, Kaunitz AM: Do mechanical methods of cervical ripening increase infectious morbidity? A systematic review. American Journal of Obstetrics \& Gynecology. 2008; $199(2): 177-187$.

6. Vaknin Z, Kurzweil Y, Sherman D. Foley catheter balloon vs locally applied prostaglandins for cervical ripening and labor induction: a systematic review and meta- American journal of obstetrics and gynecology. 2010; 203(5):418-429

7. Lueth GD, Kebede A, Medhanyie AA. Prevalence, outcomes and associated factors of labor induction among women delivered at public hospitals of MEKELLE town: A hospital based cross sectional study. BMC Pregnancy Childbirth.2020; 20:

8. Robson S, Pridmore B, Dodd J. Outcomes of induced labour. Aust N Z J Obstet Gynaecol. 1997;37:169.

9. Lydon-Rochelle MT, Ca'rdenas V, Nelson JC, Holt VL, Gardella C, Easterling TR. Induction of labor in the absence of standard medical indications: Incidence and correlates. Med Care. 2007;45:505-12.

10. Coonrod DV, Bay RC, Kishi GY. The epidemiology of labor induction: Arizona, 1997. Am J Obstet Gynecol. 2000; 182:1355-62.

11. Zhang J, Yancey MK, Henderson CE. National trends in labor induction 1989-1998. J Reprod Med. 2002; 47: 120 - 124

12. Laughon SK, Zhang J, Grewal J, Sundaram R, Beaver J, Reddy UM. Induction of labor in a contemporary obstetric cohort. Am J Obstet Gynecol. 2012; 206: 486-489.

13. Fawole B, Nafiou I, Machoki M, Wolomby-Molondo J, Mugerwa K, Neves I et al. Unmet need for Induction of Labor in Africa: Secondary analyses from the 2004 - 2005 WHO Global Maternal and Perinatal Health Survey (A cross sectional survey). BMC Public Health. 2012; 12:722.

14. World Health Organization. Neonatal and perinatal mortality: country, regional and global estimates. Available at https://apps.who.int/iris/handle/10665/43800 Accessed 30 April 2020.

15. Thomas J, Kavanagh J, Anthony K. RCOG Evidence-based Clinical Guidelines Induction of labour. 2001. 
16. Yeast JD, Jones A, Poskin M. Induction of labor and the relationship to cesarean delivery: a review of 7001 consecutive inductions. Am J Obstet Gynecol. 1999;180:628-33.

17. Sanchez-Ramos L. Induction of labour. Obstet Gynecol Clin North Am. 2005;32:181-200.

18. The World Health Organization. Recommendations for induction of labor. https://www.who.int/reproductivehealth/publications/maternal_perinatal_health/9789241501156/en/. Accessed 30 April 2020.

19. Cammu H, Martens G, Ruyssinck G, Amy JJ. Outcome after elective labor induction in nulliparous women: a matched cohort study. Am J Obstet Gynecol. 2002;186:240-4.

20. Vrouenraets FP, Roumen FJ, Dehing CJ, Van den Akker ES, Aarts MJ, Scheve EJ. Bishop score and risk of cesarean delivery after induction of labor in nulliparous women. Obstet Gynecol. 2005;105:690-7.

21. Induction of Labour. Royal College of Obstetricians and Gynaecologists. Available: http://www.rcog.org.uk. Accessed 30 April 2020.

22. Macer J, Macer C, Chan L, Fearl J. Elective induction versus spontaneous labor: a retrospective study of complications and outcome. Am J Obstet Gynecol. 1992; 1690-1696.

23. Guerra G, Cecatti J, Souza J. Elective induction versus spontaneous labour in Latin America. Bull World Health Organ. 2011; 89: 657-665.

24. Stock S, Ferguson E, Duffy A, Ford I. Outcomes of elective induction of labour compared with expectant management: population-based study. BMJ. 2012; 344: e2838.

25. Fawole B, Nafiou I, Machoki M, Wolomby-Molondo J, Mugerwa K, Neves I et al. Unmet need for Induction of Labor in Africa: Secondary analyses from the $2004-2005$ WHO Global Maternal and Perinatal Health Survey (A cross sectional survey). BMC Public Health. 2012; 12:722.

26. Mahande JM, Daltveit AK, Mmbaga BT, Obure J, Masenga G, Manongi R, et al. Recurrence of perinatal death in northern Tanzania: a registry-based study. BMC Pregnancy Childbirth. 2013; 13:166.

27. World Health Organization. Recommendations for induction of labor. https://www.who.int/reproductivehealth/publications/maternal_perinatal_health/9789241501156/en/. Accessed 30 April 2020.

28. Guerra GV, Cecatti JG, Souza JP, Faundes A, Moruiss SS, et al. Factors and outcome associated with induction of labor induction in Latin America. BJOG An International Journal of Obstetrics and Gynaecology. 2009; 116(13): 1762 - 1772.

29. Grobman WA, Rice MM, Reddy UM, Tita AT, Silver RM, Mallet G, et al. Labor Induction versus Expectant Management in Low-Risk Nulliparous Women. N ENG J 2018; 379:6

30. Salahuddin M, Davidson C, Lakey DL, Patel DA. Characteristics Associated with Induction of labor and delivery route among primiparous women with term deliveries in the listening to Mothers III Study. J Womens Health. 2018; 27(5):590-598.

31. Sinkey RG, Lacevic J, Reljic T, Hozo I, Gibson KS, Odibo AO, Djulbegovic B, Lockwood CJ. Elective induction of labor at 39 weeks among nulliparous women: The impact on maternal and neonatal risk. PLoS One. 2018; 25;13(4):e0193169. 
32. Lydon-Rochelle MT, Cardenas V, Nelson JC, Holt VL, Gardella C, Easterling TR. Induction of labor in the absence of standard medical indications: Incidence and correlates. Med Care. 2007; 45:505-12.

33. Boulvain M, Marcoux S, Bureau M, Fortier M, Fraser W. Risk of Induction of labor in uncomplicated term pregnancies. Paediatric Perinat Epidemiol. 2001; 15:131-8.

34. Le Ray C, Carayol M, Breart G, Goffinet F. Elective induction of labor: failure to follow guidelines and risk of cesarean delivery. Acta Obstet Gynecol Scand. 2007; 86:657-65.

35. Coonrod DV, Bay RC, Kishi GY. The epidemiology of labor induction. Am J Obstet Gynecol. 2000; 182:1355-62. doi:10.1067/mob.2000.106248.

36. Zhang J, Yancey MK, Henderson C. U.S. national trend on labor induction, 1989-1998. J Reprod Med 2002; 47:120-4.

37. Guerra GV, Cecatti JG, Souza JP, Faundes A, Morais SS, Gulmezoglu AM et al. Elective induction versus spontaneous labour in Latin America. Bull World Health Organ. 2011;89:657-665.

38. Thangarajah F, Scheufen P, Kirn V, Mallmann P. Induction of labor in late and postterm pregnancies and its impact on maternal and neonatal outcome. Geburtshilfe Frauenheilkd. 2016; 76(7):793-798.

39. Bodner-Adler B, Bodner K, Pateisky N, Kimberger O, Chalubinski K, Mayerhofer K, et al. Influence of labor induction on obstetric outcomes in patients with prolonged pregnancy. Wien Klin Wochenschr. $2005 ; 117,287-292$.

40. Simhayoff N, Sheiner E, Levy A, Hammel RD, Mazor M, Hallak M. Induce or not to induce labor: A macrosomic dilemma. Gynecol Obstet Invest. 2004;58:121-125.

41. Marchi, J., Berg, M., Dencker, A., Olander, E. K., \& Begley, C. Risks associated with obesity in pregnancy, for the mother and baby: a systematic review of reviews. Obesity Reviews. 2015; 16(8), 621-638.

42. Vernini JM, Moreli JB, Magalhaes CG, Costa RA, Rudge MV, Calderon MP. Maternal and fetal outcomes in pregnancies complicated by overweight and obesity. Reprod Health.2016; 27;13(1):100.

43. Nuthalapaty FS, Rouse DJ, Owen J. The association of maternal weight with cesarean risk, labor duration, and cervical dilation rate during labor induction. Obstet Gynecol. 2004;103:1019.

44. Grobman WA, Rice MM, Reddy UM, Tita AT, Silver RM, Mallet G, et al. Labor Induction versus Expectant Management in Low-Risk Nulliparous Women. N ENG J MED. 2018: 379;6.

45. Sanchez-Ramos L, Bernstein S, MD, Kaunitz Expectant management versus labor induction for suspected fetal macrosomia: a systematic review. The American College of Obstetricians and Gynecologists. 2002; 100(5): 997 - 1002.

46. Tarimo CS, Mahande MJ, Obure J. Prevalence and risk factors for caesarean delivery following labor induction at a tertiary hospital in north Tanzania: a retrospective cohort study (2000-2015). BMC Pregnancy Childbirth. 2020; 20(1):173.

47. Darney BG, Snowden JM, Cheng YW, Jacob L, Nicholson JM, Kaimal A, et al. Elective induction of labor at term compared with expectant management. Obstet Gynecol. 2013;122(4):761-769.

48. Lappen JR, Hackney DN, Bailit JL. Outcomes of term induction in trial of labor after labor after cesarean delivery. Obstetrics \& Gynecology. 2015; 126 (1):115-123. 
49. Stock S, Ferguson E, Duffy A, Ford I. Outcomes of elective induction of labor compared with expectant management: population-based study. BMJ. 2012; 10:344:e2838.

50. Lin C, Raynor D. Risk of uterine rapture in labor induction of patients with prior cesarean section: An inner-city hospital experience. Am J of Obstet Gynecol. 2004; 190:1476-8.

51. Ravasia DJ, Wood SL, Pollard JK. Uterine rupture during induced trial of labor among women with previous cesarean delivery. Am J of Obstet Gynecol. 2000; 183:1176-9.

52. Pregnancy complications: Uterine Rapture. Available at https://www.healthline.com/health/pregnancy/complications-uterine-rupture. Accessed 30 April 2020.

\section{Figures}

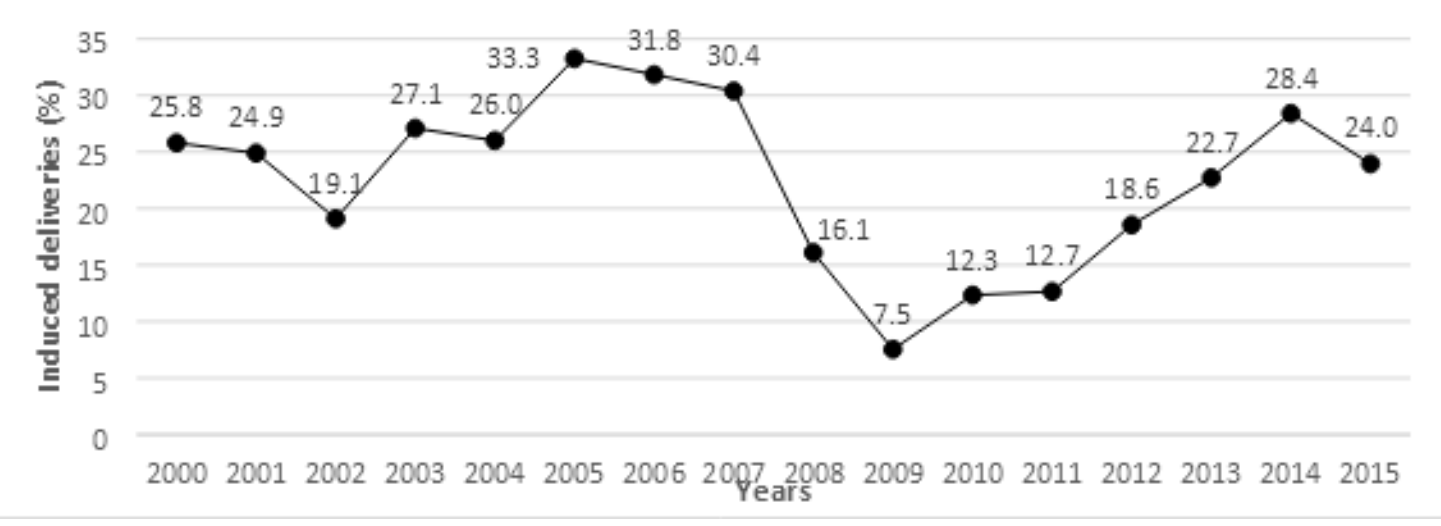

\section{Figure 1}

rend of labor induction (IOL) during the year 2000 - 2015 